\title{
Hull Design of Solar Powered Recreational Electric Boat for Indonesian Waters
}

\author{
Sunaryo Sunaryo ${ }^{1, *}$, Fahmi Yusro $^{2}$ \\ ${ }^{1}$ Naval Architecture and Marine Engineering Study Program, Mechanical Engineering Department, Universitas Indonesia Depok 16424 \\ Indonesia \\ ${ }^{2}$ Naval Architecture and Marine Engineering Study Program, Mechanical Engineering Department, Universitas Indonesia Depok 16424 \\ Indonesia
}

\begin{abstract}
Indonesia with its more than 17,000 islands and its geographical location as tropical country is blessed with many marine tourism destinations such as beautiful beaches and coral reefs, coastal community culture etc., in fact tourism is ranked as 3rd highest foreign income. On the other hand Indonesian government is also committed to promote the use of environmentally friendly new and renewable energy as an alternative to the fossil fuel which highly contribute to the air pollution. In conjunction with government's program in developing the marine tourism and in using green energy, the research is aimed to design solar powered recreational boat for tourism in Indonesia. The paper is focused on the design of the boat structure such as the hull type, the environmental friendly material for the boat hull, the arrangement of the boat that would suitable to be powered with solar energy etc. For this purpose references are obtained from literature study, experts' opinion, and previous experiments.
\end{abstract}

\section{Introduction}

Indonesia is the largest archipelagic country in the world consisting of 17,499 islands. From the most western tip of Sabang to the eastern tip of Merauke the territory of Indonesia is around 7.81 million $\mathrm{km} 2$ consisted of 2.01 million $\mathrm{km} 2$ of land, 3.25 million $\mathrm{km} 2$ of inner sea, and 2.55 million $\mathrm{km} 2$ of Exclusive Economic Zone [1]. Seen from geopolitics and geo-economics point of view sea plays very important role for Indonesia. Not only blessed with huge number of inlands, Indonesia is also blessed with abundant of beautiful marine tourism spots such as beaches, coral reefs, coastal community cultures, and islands, which makes Indonesia as one of the world's most popular tourist destination. Indonesia is geographically located on the equator with high intensity of sun shine, which makes Indonesia very potential to tap renewable energy from sun shine [2]. The utilization of solar energy is very potential for preventing the green house effect, and air pollution from the massive consumption of fossil fuels. Refer to the above conditions the utilization of solar powered recreational boats is considered to be a special attraction for tourism in Indonesia, and therefore the research is aimed to design a solar powered recreational boat to be operated on Indonesian waters both on sea as well as on inland waters such as lakes and rivers. The utilization of solar powered recreational boats is. not only contribute to reduce the green house effects but would also provide economic growth to the local community, and in the long run the concept of solar powered boat can also be extended to other purposes such as fishing vessels, river transportation etc.

Currently tourism or traveling has become a lifestyle for most of the world community, including those who make Indonesia as their destination. This is evidenced by the increasing number of tourists that visit Indonesia [3] as shown by statistical data presented on figure 1 .

International Visitor Arrivals Statistics Indonesia

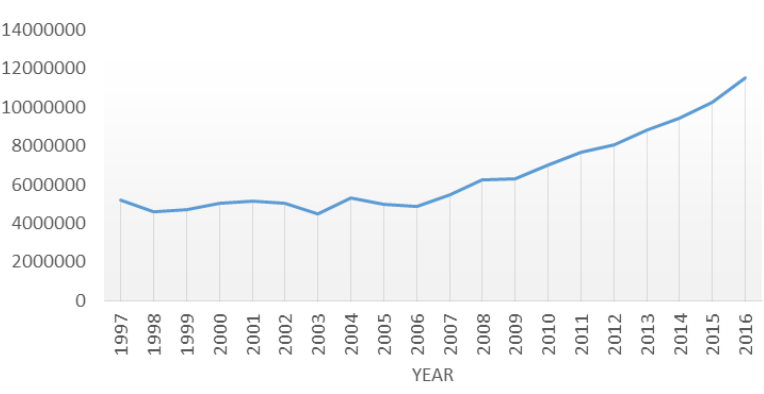

Figure 1. International Visitors Arrival Statistics Indonesia.

The study is part of the research on the design of solar powered recreational boat to be operated on Indonesian waters, and focused on the aspects of its hull structural design including the boat's stability.

\section{Methodology and Results}

Figures the methodology used in this study is mainly based on the modeling and simulation approaches, which

Corresponding author: naryo@eng.ui.ac.id 
started with problems identification and the hypothesis on how to solve the problems, followed by defining the objective of the study. Comprehensive literature study and a field survey were conducted in order to collect reliable data and information related to the study. The results of the analyses are verified in accordance to their relevance to the objectives of the study.

The study is consisted of three related aspects i.e. consideration of hull types, determining the main dimensions, and analyzing the boat's stability in three different loading conditions, which include at the empty condition, half full condition, and full loaded condition.

\subsection{Hull Type}

The first stage of the study is to determine the hull type that is most suitable for the solar powered recreational boat. Hull is defined as the watertight body of a ship or boat that forms as an envelope that provides buoyancy to the ship or boat [4]. In determining the type of hull, we need to consider several factors like the purpose of the boat, the total passenger will be carried, the operating environment, and the loading conditions. The purpose of the boat under consideration is to carry passengers who are enjoying the water spots where the boat is being operated, therefore it should provide comfort for the passengers, and the number of passengers and crews is suggested to be around 12 persons.

From the number of hulls points of view in general there are two type hulls being used for recreational boats i.e. mono-hull and multi-hull. In order to provide comfort and good stability it is decided that multi-hull is to be used for the boat being proposed, and in more specific is catamaran hull type.

Catamaran [5] is consisted of two hulls bridged by a deck or several beams depended on the design purposes, some outstanding characteristics of catamaran hull are that it has more stability compared to mono-hull boat especially that this boat has solar PV panels on its roof which make the distance of centre of gravity of the boat from its keel is higher, good stability will provide comfort to passengers, the slim twin hulls have little drag and hence will reduce boat resistance, with more buoyancy created by two hulls generally catamaran will have a shallower draft, and requires smaller engines than similarly sized of mono hull boat [6].

Though the construction of catamaran is based on the same principles as those of a conventional monohull, there are few main differences that make the former more stable and faster [7]. The salient feature of catamarans is that it is lighter than the conventional mono-hull, mainly due to their thinner hull cross-section, and the absence of keel counter-weight that makes catamaran boat requires less engine power for the same determined service speed, which is very useful for solar powered boat. The higher stability of catamaran is provided by a wider beam that allows the boat to carry more load area per unit length The greater stability allows the catamaran to carry consider weight of PV panels on its roof. Concept of catamaran hull is presented on figure 2 .

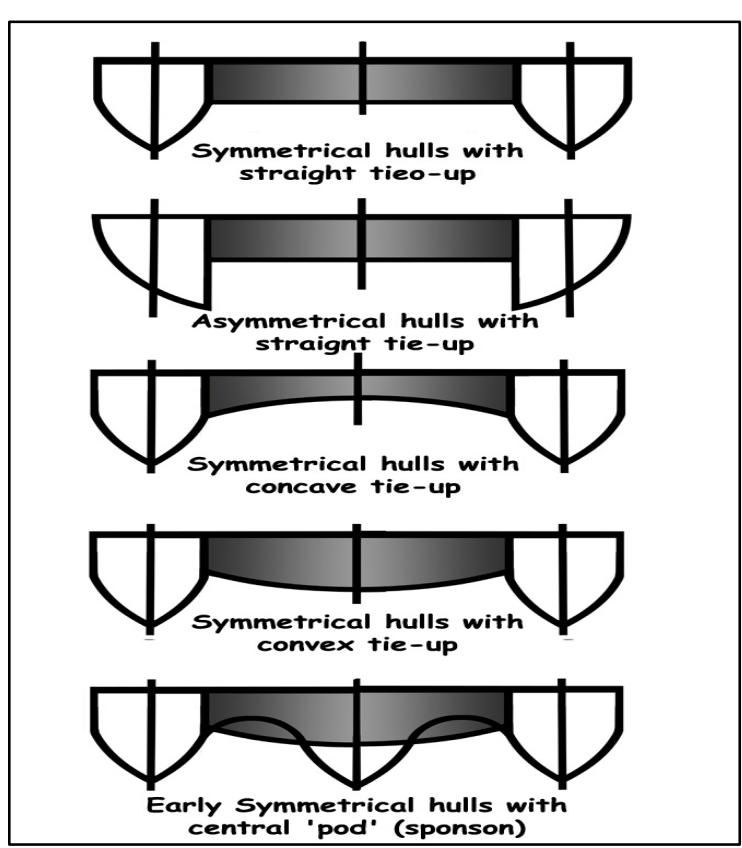

Figure 2. Catamaran Hull Concept

\subsection{Hull Dimensions}

Hull is the watertight body of a boat. Some understandings of the hull's parts is important for calculating the boat design, these include the line where the hull meets the water surface is called the waterline, the outer most of the hull's length is called length over all, the length between the front water line and the axis of the rudder is called length between perpendiculars, the outer most breadth of the hull is called breadth molded, the boat's draft is the vertical distance amidships is called the boat's free board. From the boat's keel to the water line, and the distance from the water line to the hull's deck at a midship of the boat is called the boat's free board [8]. Information regarding the ship's hull parts measurement is presented in figure 3 .

In this study catamaran hull type is decided to be used in order to achieve good stability and comfort to the passengers [9]. Takes into account the number of passengers to be carried and the operational environment the boat is designed as shown in figure 4, and its layout in figure 5. With main dimensions as presented in table 1.

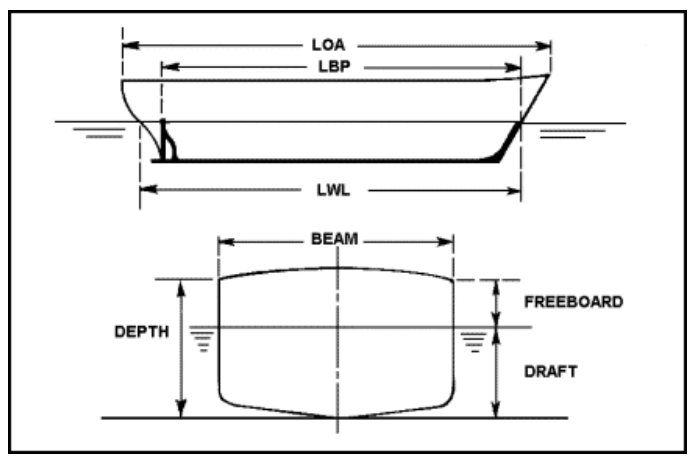

Figure 3. Boat main dimension 


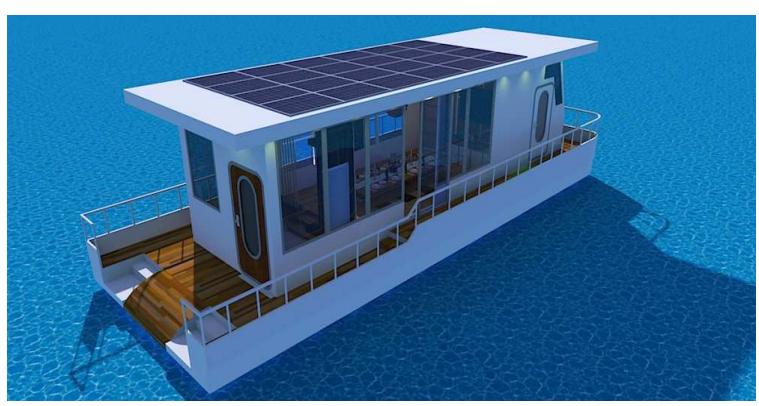

Figure 4. Boat design

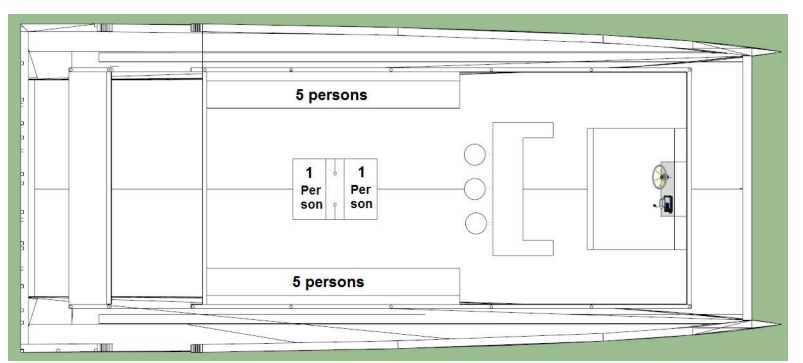

Figure 5. Boat layout

Table 1. Font styles for a reference to a journal article

\begin{tabular}{lc} 
Particulars & Dimension (m) \\
\hline Length over all & 12.64 \\
\hline Length between perpendiculars & 12.13 \\
Breadth molded & 5.39 \\
Draft & 0.70 \\
\hline
\end{tabular}

\subsection{Stability}

recreational boat is analyzed in 3 different conditions i.e. full loaded condition, where the boat is assumed just being ready for operation with full capacity of passengers and crews, provisions, batteries, fresh water etc.; half full condition, where the number of passengers and crews is only a half of its capacity as well as the provisions, fresh water etc.; and empty condition, where the boat is assumed the boat is being tied to the jetty with no passenger and crew, no provision, and no fresh water in it. The stability analysis is simulated using Maxsurf stability software [10]. The most important factor in the stability analysis is the value of righting angle $\Theta$ at the maximum righting lever GZ (the distance between vertical lines of gravity and boat's buoyancy) to see if the boat is still have sufficient free board to prevent water from entering the boat from its deck. International maritime Organization (IMO) requires that maximum righting angle should not less than 250, for the boat being investigated the maximum righting angle is at 580 where the water reaches the tip of the deck.

Bray [11] states that stability is the ability of a boat to return to its previous position when an external force is applied in a calm water condition, there are three type of stability conditions: positive stability when the boat is able to turn to upright position, neutral when the boat does not turn to any direction after a force is given to it, and negative stability when the boat is overturned. Stability is the relationship between the centre of all buoyancies and the boat's centre of gravity. Figure 6 shows the three stability conditions.

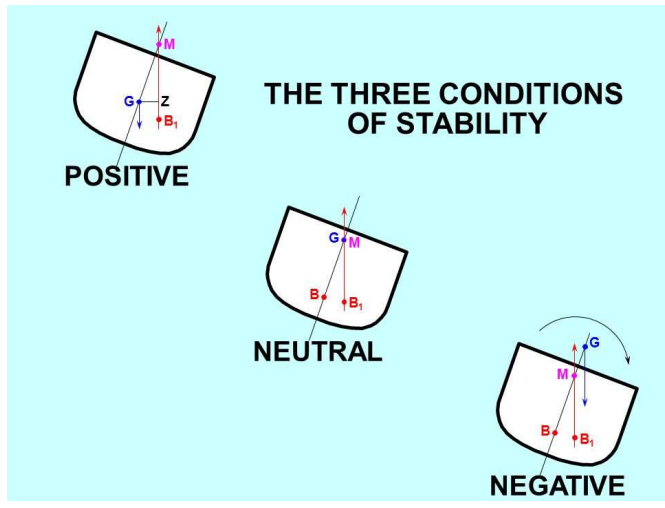

Figure 6. Three stability conditions

In this study the location of the weight of each component of the boat is assumed to be in the middle, however, the location of the weight of the empty ship (lightship) is taken based on the calculation results from Maxsurf simulation.

Figure 7 presents the stability graph showing the value of righting lever at the maximum righting angle at the empty boat condition.

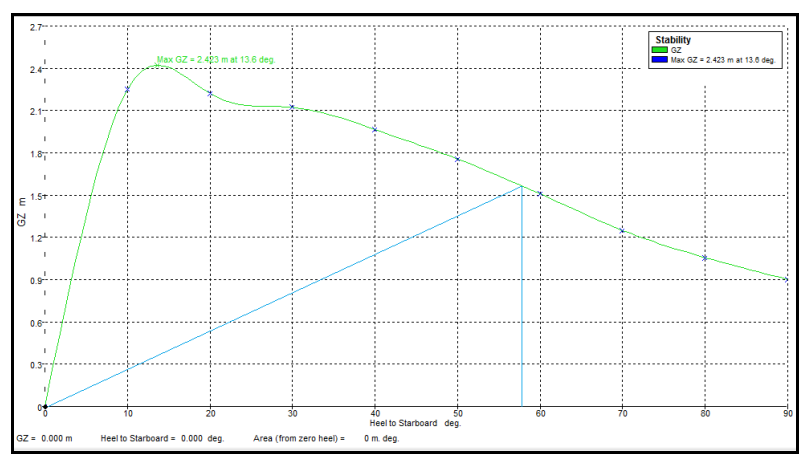

Figure 7. Stability graph showing GZ at slope angle of empty boat condition

When viewed from the stability curve, it is evident that GZ is positive at the slope angle. The value of the slope angle when $\mathrm{GZ}$ reaches the maximum value on the stability meets the criteria of IMO i.e. not less than $25^{\circ}$. This indicates that the boat is stable at the empty condition.

Figure 8 presents the stability graph showing the value of righting lever at maximum righting angle at the half loaded boat condition. 


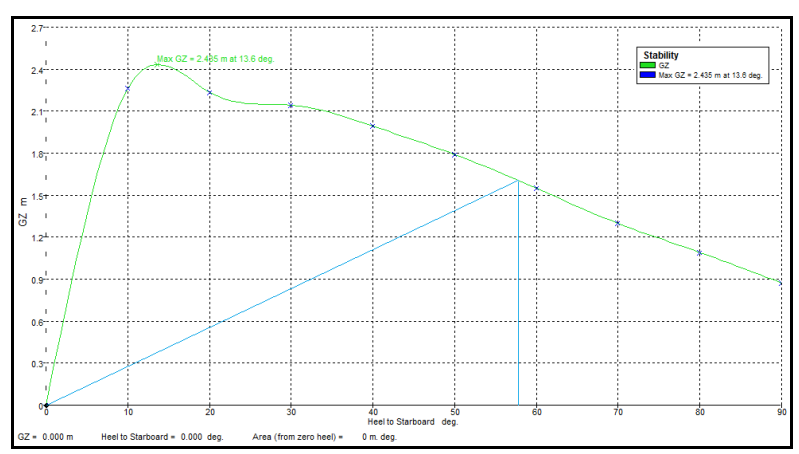

Figure 8. Stability graph showing GZ at slope angle of half loaded boat condition

It can be seen that at the half loaded boat condition the GZ is still positive at the slope angle, and this means that the boat is in stable condition.

Figure 9 presents the stability graph showing the value of righting lever $\mathrm{GZ}$ at maximum righting angle at foul loaded boat condition.

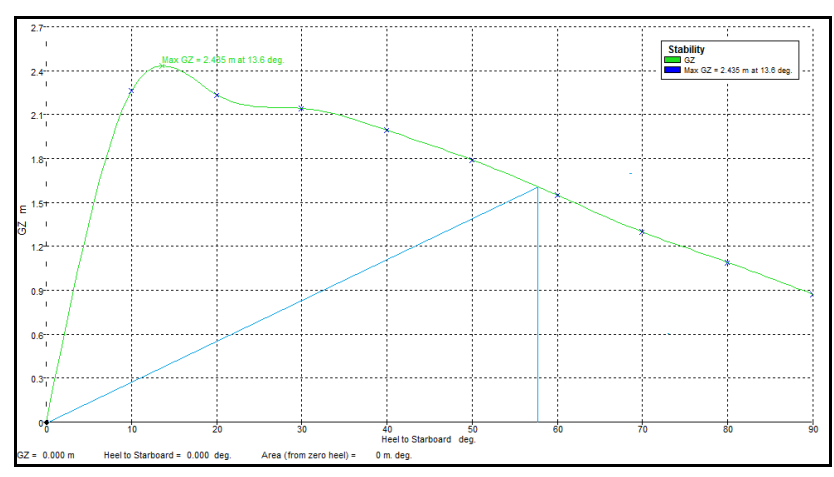

Figure 9. Stability graph showing GZ at slope angle of fully loaded boat condition

It can be seen that at the full loaded boat condition the GZ is still positive at the slope angle, and this means that the boat is in stable condition.

\section{Conclusion}

Catamaran hull is decided to be used for the proposed solar powered recreational boat, because it has many advantages compared to conventional monohull boat.

The stability of this solar-powered vessel is proven to be excellent and matches the standards set by IMO

\section{Acknowledgement}

The Authors would like to appreciate Directorate of Research and Community Engagement Universitas Indonesia for providing fund through Hibah Publikasi Internasional Terindeks Untuk Tugas Akhir Mahasiswa (PITTA) 2018 scheme Contract number 2541/UN2.R3.1/HKP.05.00/2018, for carrying out and publishing the research and its results, and the Solar Boat Competition team of Department of Mechanical Engineering, Naval Architecture study program
Universitas Indonesia for providing support and encouragement..

\section{References}

1. National Law development Agency Ministry of Justice and Human Right Republic of Indonesia, (2015), Indonesian Island States Is the Largest in the world, Warta BPHN, 28 October 2015.

2. Indonesian Geographical Science Centre, (2015), Pengaruh Letak Astronomis dan Geografis Indonesia terhadap kondisi Iklim (Effect of Indonesia's Astronomical and Geographical Location to the Climate Condition), Ilmu Geografi.com, 3 October 2015.

3. Lestari and Kanti T, (2017), International Visitor Arrivals Statistics, Indonesia. Central of Statistical Bureau (BPS) Catalog No. 8401011.

4. Chakreborty S, (2017), Hull of A ship, Understanding design and Characteristis, Marine Insight, 27 December 2017.

5. Watson DGM, (1997), Practical Ship Design, Elsevier, pp $46-53$.

6. Karinen J, (2011), Power catamaran Design Study, Lahti University of Applied Science, Graduation Project, pp $30-38$

7. Catamaran guru, (2018), Catamaran vs. Monohull we change should you? https://catamaranguru.com

8. Tupper EC, (2013), Introduction to Naval Architecture, Butterworth - Heinemann, pp 9-32.

9. G. Spagnolo, "Solar-Electric Boat," Journal of Transportation Technologies, pp. 144-149, 2012

10. Bentley System. (2013). Maxsurf Resistance Program \& User Manual. Incorporated.

11. Bray PJ, (2014), Stability What Is it And How Does It work?, Bray Yacht Design and Research. 